\title{
Pensar para la producción audiovisual multiplataforma para la Televisión Digital
}

\author{
Thought or audiovisual production platform for Digital TV
}

\author{
Ing. Carlos G. Liendo \\ Universidad Blas Pascual (Argentina) \\ carlosliendo@gmail.com \\ Lic. Pedro A. Servent \\ Universidad Blas Pascual (Argentina) \\ pservent@gmail.com
}

Recibido: 8 de Diciembre de 2010 Aceptado: 13 de Febrero de 2011

\section{Resumen}

El permanente y acelerado avance de las tecnologías aplicadas a la producción de materiales audiovisuales y su difusión en los medios masivos de comunicación, está provocando escenarios y situaciones particulares que recién están siendo analizados hace escaso tiempo y que quizás constituyan una característica esencial del proceso de convergencia actual. A esta particularidad debemos sumarle la fragmentación de mensajes y la diversidad de las audiencias, con lo cual podríamos afirmar que deben cambiar los modos y maneras de contar historias y concebir los mensajes audiovisuales. Producción en Multiplataforma se refiere a la creación de productos audiovisuales que logran una alta eficacia comunicativa en diversas plataformas, considerando y aprovechando las características propias de cada una y que brindan una alta experiencia de usuario por cualquier camino de acceso. Tomaremos a las plataformas, desde el punto de vista de los productos audiovisuales, como los distintos sistemas de transmisión, distribución y tecnologías de visualización utilizados por los televidentes o usuarios de los productos audiovisuales. Cada uno tiene determinadas características e influyen sobre la forma en que se visualizan y cómo se relacionan con el usuario. Las plataformas tradicionales para la distribución de productos audiovisuales son el cine, la televisión analógica y el vídeo analógico. Considerados estos, desde el punto de vista de la producción de contenido como soportes tecnológicos, han crecido y evolucionado incluso en la reciente era digital en mayor medida han mantenido cierta compatibilidad a lo largo del tiempo y no han modificado su esencia y linealidad a la hora de emitir. Con la digitalización del video y la televisión han 
aparecido muchas otras plataformas, que están en constante evolución. El objetivo de este trabajo es identificar las distintas plataformas y proponer un acercamiento a la producción audiovisual más adecuada pensada para multiplataforma.

Palabras Clave: Producción, televisión, digital, plataformas

\section{Introducción}

El permanente y acelerado avance de las tecnologías aplicadas a la producción de materiales audiovisuales y su difusión en los medios masivos de comunicación, está provocando escenarios y situaciones particulares que recién están siendo analizados hace escaso tiempo y que quizás constituyan una característica esencial del proceso de convergencia actual. A esta particularidad debemos sumarle la fragmentación de mensajes y la diversidad de las audiencias, con lo cual podríamos afirmar que deben cambiar los modos y maneras de contar historias y concebir los mensajes audiovisuales.

El término multiplataforma ${ }^{i}$ es utilizado desde hace un tiempo en el ámbito informático para referirse a los programas, sistemas operativos, lenguajes de programación u otra clase de software, que puedan funcionar en diversas plataformas, aquí lo usaremos en lo relativo a las diversas posibilidades que tienen los distintos productos audiovisuales para llegar al destinatario o audiencia.

Estas audiencias hoy tienen la posibilidad de utilizar distintos dispositivos para acceder a los productos audiovisuales y por ello pueden acceder a la información por diversos sistemas técnicos.

El objetivo de este trabajo es identificar las distintas plataformas y proponer un acercamiento a la producción audiovisual más adecuada pensada para multiplataforma.

\section{Antecedentes}

En la República Argentina, se lleva a cabo una transformación en cuanto a las comunicaciones audiovisuales, tendiente a lograr un mayor pluralismo en las comunicaciones. Motor fundamental de ello es la promulgación, implementación y puesta en marcha de la Ley de Servicios de Comunicación Audiovisual № $26522^{\mathrm{ii}}$. 
Uno de los puntos fuertes que trae aparejada la reglamentación de esta Ley es el desarrollo de la televisión digital, la cual incide sobre los servicios de televisión abierta y gratuita que hasta el momento se mantienen en un entorno analógico.

El $1^{\circ}$ de septiembre de 2009 se publicó en el Boletín Oficial de la República Argentina el Decreto 1148/2009iii, por el cual se crea el Sistema Argentino de Televisión Digital Terrestre (SATVD-T) y se recomienda la creación del Consejo Asesor de Televisión Digital. Nuestro país adoptó la norma ISDB-Tb (Integrated Services Digital Broadcasting Terrestrial (Brasil) o Transmisión Digital de Servicios Integrados Terrestres), el cual es un estándar de televisión digital por aire basado en el sistema original japonés ISDB-T y modificado por Brasil. Este país ya inició sus servicios comerciales y públicos el 2 de diciembre de 2007.

La Televisión Digital por Aire y gratuita está movilizando la industria de la tecnología, del software y de los contenidos en todo el territorio nacional; se están implementado políticas de inclusión social mediante la distribución gratuita de decodificadores de TVD en hogares de bajos recursos y se ha potenciado la participación de las Universidades estatales y privadas en el desarrollo de polos de creación de contenidos audiovisuales, que son los componentes esenciales para que la TV Digital se inserte en la población. También se han creado polos de I+D para la fabricación de los decodificadores, televisores, transmisores, programas informáticos, etc.

Uno de los objetivos del SATVD-T es hacer llegar la TV libre y gratuita a todos los rincones del país, para ello ha planificado una plataforma de emisión que incluye las principales ciudades del país y un servicio de televisión directa al hogar por satélite, para cubrir en aproximadamente cuatro años el $100 \%$ de los habitantes.

El principal problema que se debe afrontar hoy para el éxito de esta propuesta de modificación del panorama de los medios, es la necesidad de programación, en cantidad y calidad. Es importante tener en cuenta que en el corto plazo serán necesarias unas 4000 horas de programación para cubrir todas las señales.

Con la introducción de las tecnologías digitales en los medios, ya sea la telefonía, la TV por Cable, la Radio o la Televisión por aire, o sea los distintos servicios que utilizan bits para sus procesos, encuentran una gran cantidad de puntos en común en su forma de transmisión, de proceso y de almacenamiento, por lo que desde éste punto se puede visualizar una convergencia en un único sistema que utiliza bits como componente esencial, permitiendo que los distintos servicios se articulen sobre una misma tecnología. En la Figura № 1 tenemos tres áreas: Telecomunicaciones, Medios Audiovisuales e Internet y vemos que muy aceleradamente se van fusionando y adquieren innumerables puntos en común. 
Figura I : Convergencia

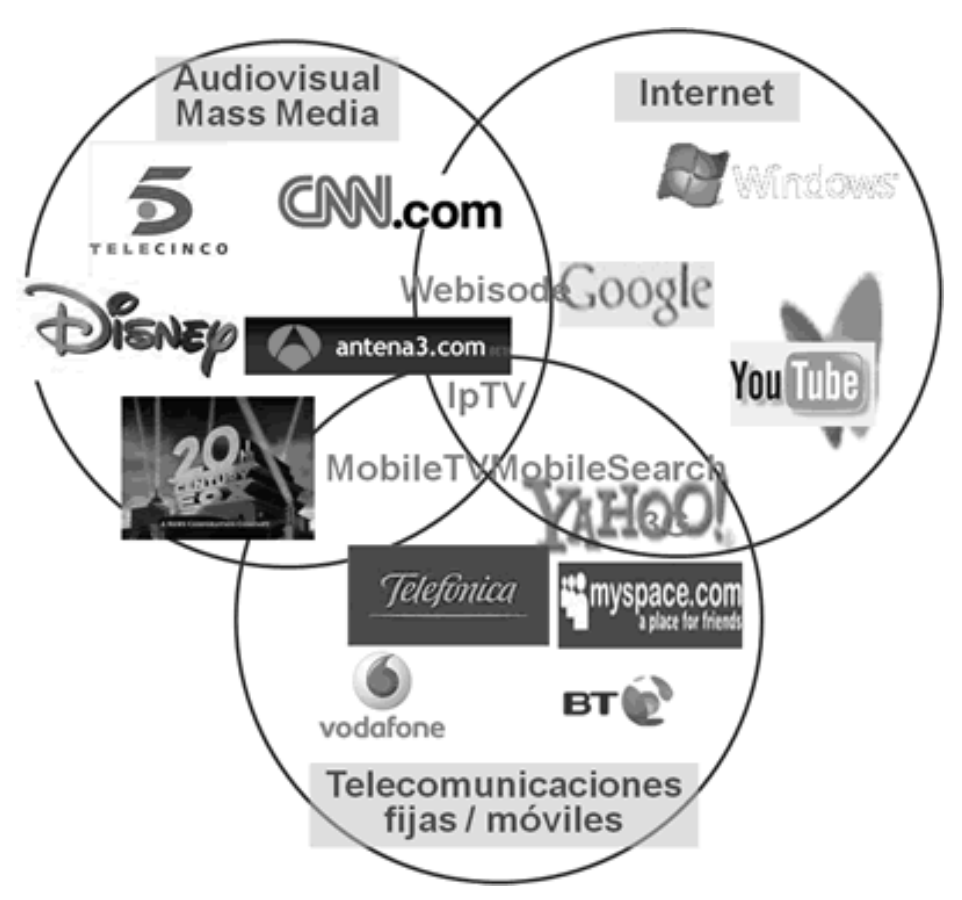

Fuente: IX Foro de Regulación en las Telecomunicaciones - AHCIET, Audiovisual y Telecomunicaciones:Dos mundos una realidad. Telefónica España Alberto Moreno, Director de Política Regulatoria. 4 de Junio, 2008

La digitalización ha modificado de raíz todos los procesos esenciales atribuidos al trabajo de búsqueda, elaboración y difusión de contenidos informativos. De hecho, el propio concepto de medio de comunicación ha mutado a raíz de la rápida confluencia entre la industria audiovisual, la informática y las telecomunicaciones (Zaragoza, 2002).

\subsection{Multiplataforma: el futuro audiovisual}

Es indispensable que para lograr una mayor eficacia comunicativa e impacto en los televidentes, se adapte el contenido audiovisual a las particularidades de cada medio y/o dispositivo técnico de recepción, o sea, a cada plataforma.

Esta eficacia se traduciría en una mejor decodificación del mensaje por parte del usuario desde el punto de vista de los realizadores audiovisuales, con producciones a menor costo operativo, reducción de los tiempos de trabajo, captación de nuevos públicos y ampliación de las posibilidades de retroalimentación emisor/receptor y viceversa. 
Tal adaptación no solamente se refiere a la conversión desde los formatos tradicionales a los nuevos sistemas y dispositivos tecnológicos o el diseño de los contenidos audiovisuales teniendo en cuenta un específico formato, sino a considerar la diversidad de medios y dispositivos que hoy existen y concebir un producto desde la idea y en todos los procesos intermedios hasta su elaboración completa, teniendo en cuenta la posibilidad de difusión en multiplataforma audiovisual.

Se trata así de crear o diseñar productos audiovisuales para que sean distribuidos a muchos usuarios por distintos medios y dispositivos y que en cada momento la comunicación, sea la más efectiva al considerar las propias características de cada dispositivo de distribución tecnológica.

El trasvase de formatos y contenidos desde la televisión tradicional a los nuevos medios constituye una práctica habitual y no considera las propias características de dispositivos, redes o sistemas de comunicación que están en uso a partir de la digitalización del video y la televisión. Está claro que una de las características de la TV Digital consiste en la posibilidad de constituirse como distribuidor de contenidos electrónicos en lugar de la TV analógica que simplemente es distribuidora de audio y vídeo. También es preciso recalcar que la TV Digital compite de manera constante y hasta de manera desigual con la interactividad y el dinamismo planteado por los continuos cambios de Internet.

Si se consideraran éstas nuevas características tecnológicas y hasta de comportamiento del usuario, se obtendría una mayor eficacia comunicativa.

\section{2. ¿A qué llamamos Multiplataforma?}

Las plataformas en su concepción informática, definen un estándar alrededor del cual un sistema puede ser desarrollado ${ }^{\text {iv }}$

Tomaremos a las plataformas, desde el punto de vista de los productos audiovisuales, como los distintos sistemas de transmisión, distribución y tecnologías de visualización utilizados por los televidentes o usuarios de los productos audiovisuales. Cada uno tiene determinadas características e influyen sobre la forma en que se visualizan y cómo se relacionan con el usuario.

Producción en Multiplataforma se refiere a la creación de productos audiovisuales que logran una alta eficacia comunicativa en diversas plataformas, considerando y aprovechando las características propias de cada una y que brindan una alta experiencia de usuario por cualquier camino de acceso. 
Las plataformas tradicionales para la distribución de productos audiovisuales son el cine, la televisión analógica y el vídeo analógico. Considerados estos, desde el punto de vista de la producción de contenido como soportes tecnológicos, han crecido y evolucionado incluso en la reciente era digital en mayor medida han mantenido cierta compatibilidad a lo largo del tiempo y no han modificado su esencia y linealidad a la hora de emitir.

Con la digitalización del video y la televisión han aparecido muchas otras plataformas, que están en constante evolución. Quizás la mención de Internet sea sólo un ejemplo de las nuevas posibilidades.

Considerando la forma de acceso para ver los productos desde el usuario y las posibilidades de comportamiento del mismo, las Plataformas que se identifican hoy son:

- Standard Definition (SD)

Se caracteriza por una calidad media, en resolución de $720 \times 576$ pixels y se ofrece en formatos de pantalla 4/3 ó 16/9. Siendo éste el formato de pantalla medido en unidades de ancho sobre unidades de altura. Una pantalla 16/9 muestra más información que una de $4 / 3$, entonces se necesita considerar qué parte de la escena se perderá al pasar de una plataforma a otra o qué consideraciones tendremos para que no exista una deformación de la imagen.

- High Definition (HD)

La calidad de las imágenes son determinantes siendo para Full HD de $1920 \times 1080$ pixeles y generalmente el usuario cuenta con pantallas de gran tamaño (mayor a 32"), Aquí, hay que considerar el formato de pantalla de 16/9 y el proceso de conversión a SD (downconverter).

- Low Definition (LD)

Se refiere a televisión de baja definición con resoluciones del orden de 320×240 pixeles, en diversos formatos de pantalla. Se incluyen los televisores portátiles y móviles, teléfonos celulares, notebooks, netbook, iPad, etc.

- Formatos en Protocolo IP: WebTV, IPTV, Youtube y otras

En este caso denominamos plataforma a las distintas posibilidades tecnológicas de distribución de contenidos por Internet y que dependen principalmente de las bajas velocidades de transferencia de datos.

- Datos: incorporación de datos adicionales a las producciones 
Aquí el concepto de Plataforma se relaciona a las posibilidades de incorporar datos adicionales a los productos audiovisuales, que permiten ofrecer información alternativa al televidente, como ser: nombre de actores, historiales, reseñas escritas, descripción de productos, etc. En general no se ofrece interactividad completav y si existe es solamente localvi.

- Interactividad: por canal de retorno en la misma red u otras

Esta posibilidad para el usuario constituye en sí una plataforma porque implica una modalidad de acceso al producto audiovisual que se combina con la interacción con servidores existentes en Internet. Esto permite que el producto audiovisual pueda aprovechar ese esquema de interacción para distintos servicios: oferta de productos relacionados al material audiovisual, acceso a información adicional existente en Internet, registro de usuario, concursos, votaciones, etc.

- Plataformas de Videojuegos

Los videojuegos se utilizan ampliamente en el hogar a través de consolas y constituyen en sí una plataforma que puede trabajar de manera independiente a la televisión e incluso a Internet o puede estar relacionada, según la tecnología de la consola. Los productos audiovisuales para multiplataforma deberían considerar la adaptación del producto a éstas consolas y aprovechar las amplias posibilidades de comunicación que ofrecen.

- Dispositivos ópticos, DVD y Blue-Ray

Estos soportes de datos de características ópticas constituyen un estándar audiovisual para el hogar y han logrado una alta penetración y uso extendido. Ofrecen interacción local, por ejemplo: la división en capítulos, incorporación de fotografías, esquemas de navegación dentro de la producción, etc.

- Plataformas desde las formas del relato

Las nuevas posibilidades en el campo de la comunicación audiovisual, si bien en su mayoría tienen sus raíces en lo tecnológico, también presentan modalidades aún no exploradas, que adecuadamente entendidas ayudarían a generar nuevas formas de relatos. Al diversificarse las señales con mayor calidad se presenta la posibilidad de multiplicar las señales simultáneas de un mismo hecho, ampliando así las miradas de lo que en TV analógica era decisión privativa del director que elegía lo que el espectador veía finalmente en 
su televisor. Ya ha sido probado en eventos deportivos y realitys televisivos la posibilidad del espectador de poder elegir la cámara con la cual visualizar y cambiar entre las distintas opciones tan sólo desde el control remoto. Actualmente no hay antecedentes de la posibilidad de brindar al espectador la decisión de elegir la cámara en el género ficción. Si bien hay experiencias en las que se puede alterar el desarrollo de acuerdo a distintas elecciones del espectador (Ilamada TV Interactiva), aun no se ha experimentado con la posibilidad de generar historias con tratamientos paralelos, tanto a nivel de historias como de su realización y producción para que el espectador disponga un menú de canales simultáneos con los que optar por distintas historias de una misma ficción. Se plantea así, la posibilidad tecnológica de generar diversas señales o transmisiones audiovisuales (TDT - Televisión Digital Terrestre) con la alternativa de descomponer un relato en tantas historias en paralelo se sucedan y que el espectador (sólo sería espectador?) tenga la posibilidad de optar a partir de la elección de cada uno de los canales por la historia que desea ver en cada momento y rever en cualquier momento las otras. La tecnología de empaquetamiento de señales de la TV Digital (Transport Stream) permitiría está posibilidad de comunicación.

Otra alternativa desde el relato es la producción audiovisual para distintos mercados, en el que el producto audiovisual se diseña en forma neutra y en cada lugar de emisión se le incorpora su propia gráfica y su publicidad (Branding), sin que se requiera una nueva edición. O sea, al momento de editar el producto se le incluye los datos en la línea de tiempo que serán utilizados por los distintos sistemas de transmisión, de diversas plantas adonde se distribuya el producto, para automáticamente insertar la gráfica que corresponda. Esta no es una práctica actual y será posible con la TV Digital.

Cada uno de estos ítem que denominamos Plataformas tienen sus propias particulares y características, esto conlleva que un mensaje deba ser diseñado específicamente para cada plataforma. En la práctica, asimismo, hay elementos de reproducción simultáneos de distintas plataformas.

\section{Metodología}

Se requiere identificar el problema para luego elaborar un conjunto de consideraciones técnicas y del relato, adecuadas para cada medio, dispositivo o plataforma. El ejemplo de los 
periódicos y su traspaso a las versiones on-line sirve como muestra: las noticias están editadas para la versión on-line y lo hacen desde el mismo origen de noticias.

La diversidad de plataformas audiovisuales vienen desde la digitalización del video y la televisión, en nuestro país se comienza a hablar desde que se aprobó la norma de televisión digital abierta (septiembre de 2009, ISDB-Tb) y de la digitalización de algunos canales que se transmiten por la TV por Cable. Si bien ya estaba presente en las transmisiones satelitales (DTH).

Para tratar de identificar el problema veamos la adaptación y creación de productos audiovisuales en HDTV y formato de pantalla 16/9 en comparación con el 4/3 convencional. Cuando se produce en 16/9 y luego se convierte a 4/3 sin deformación de las imágenes, se pierden aproximadamente un $30 \%$ de información de la imagen original. Entonces, hay una primera cuestión a resolver qué es decidir lo que se pierde sin que cambie el mensaje o cómo es conveniente producir, desde las tomas iniciales, para que se obtengan productos que se adapten a ambas plataformas (HD, SD) o mejor aún elaborar dos productos pensados u optimizados para cada plataforma. No solamente es importante el formato de la pantalla sino también la pérdida de calidad en SD y que en general las pantallas SD son más chicas que las HD.

Figura II. Conversión HD a SD

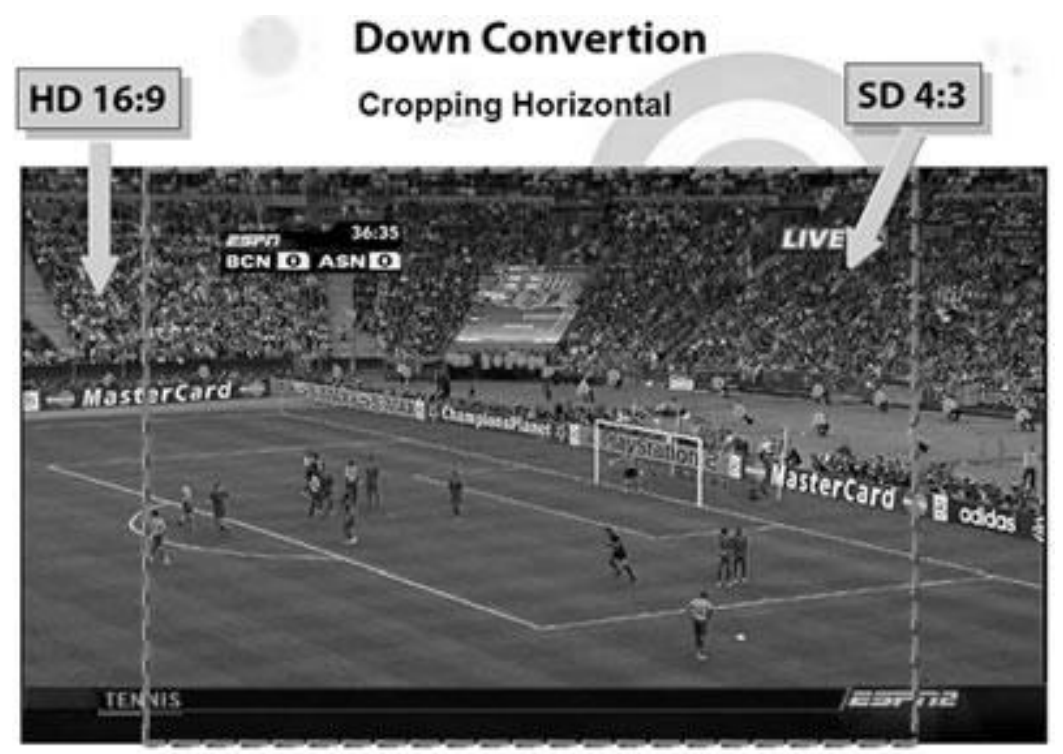

Fuente: "Nuevas Tecnologías para la comunicación en la era digital" Formatos de Producción. 5 de mayo de 2010. Ing. Oscar Nunzio. Jefe Dpto. Técnico. Gerencia de Ingeniería. Canal 7 Argentina. 
Un producto audiovisual multiplataforma debería considerar, desde el guión, las tomas adecuadas para una edición de post-producción que determine con claridad la manera de resolver este problema. O sea, generando dos productos distintos desde tomas realizadas especialmente para cada plataforma. En contrario, posiblemente una simple conversión modificaría el relato disminuyendo la eficacia de la comunicación. Esta situación es la más inmediata que se presenta con los nuevos formatos y en la actualidad está ocasionando problemas en las transmisiones de televisión digital. Hay muchas otras consideraciones, por ejemplo, entre HD y SD el audio resulta fundamental, porque normalmente el televidente que tiene HD también tiene un equipo importante de audio e incluso en sistemas 5.1.

La TV por Internet en sus distintas versiones, como WebTV o IPTV e incluso la TV por la red eléctrica o WiMax, etc., tiene sus características bien definidas por el medio que utilizan. El medio Internet tiene una gran dispersión en cuanto a las velocidades de transporte de la información. Desde el servidor de video hasta el usuario hay innumerables equipos y redes intermedias que producen retardos, pérdidas de datos, etc. El bitrate promedio que dispone el usuario es limitante en las posibilidades de ver una televisión de calidad. Esto condiciona la especificación técnica de una producción audiovisual, se debe comprimir la información al máximo, reduciendo el tamaño de la pantalla y los cuadros por segundo, a los fines de bajar significativamente el bitrate necesario para que el usuario vea adecuadamente. Una producción audiovisual para web debería contener tomas específicas para éste medio.

Los teléfonos móviles son una caso muy importante por la gran penetración que han adquirido en la población y porque todos los sistemas y normas de TV Digital incorporan transmisión para móviles. En ISDB-Tb el servicio a móviles se llama One-Seg y permite difundir uno o hasta dos señales de TV en el área de cobertura de la estación por cada canal digital. El teléfono móvil tiene grandes limitaciones por el tamaño de pantalla, su bajo bitrate, baja resolución, pobre calidad de audio, etc.

Otra posibilidad de la TV Digital es la inclusión de datos asociados al material audiovisual y la interactividad. Los datos (o Meta Datos) se agregan para ofrecer servicios adicionales y algunos televidentes podrán acceder a ellos y otros no podrán hacerlo según el decodificador que dispongan. Algo parecido pasa con la interactividad, se requiere una conexión a Internet desde el decodificador o televisor. Ambas cosas son para tener en cuenta al momento de la producción audiovisual porque es información adicional que podemos agregar con la TV Digital para reforzar el proceso de comunicación.

En definitiva el problema con que nos encontramos es que los usuarios dispondrán de una diversidad de formas de ver la TV a partir de la TV Digital. Esto complica indudablemente el 
panorama de la producción por la necesaria adaptación de los productos. Además, hay que reconocer los cambios de actitud del televidente y las tecnologías, las herramientas disponibles y su adaptación. También, cómo se modifica el lenguaje y sus estructuras en relación a duración, tiempos de atención, cuestiones técnicas como detalles, movimientos, colores, contrastes, etc. Hay procesos irreversibles en cuanto a las preferencias del público: hoy es mayoría la gente que pasa más horas expuesta a la comunicación multilateral de Internet que a los medios de comunicación tradicional analógicos, también, se estima que una de cada tres personas en Argentina tiene un celular como soporte de sus actividades diarias.

Desde lo conceptual, la producción para televisión digital no es muy diferente a la producción audiovisual clásica con sus etapas de preproducción, producción y postproducción, pero si pretende competir debe incorporar un elemento que impregna todo el proceso: la interactividad. De esta manera se agregarían nuevos y potenciales públicos.

Tradicionalmente se categorizaba las audiencia en edades, poder de compra, género, etc. (Target), ahora se agrega el tipo de dispositivo con que visualiza, la red a la que está conectado, las posibilidades de su receptor (visionado de datos adicionales y/o interactividad, etc.). Cada vez hay más segmentación hasta el punto de considerar al televidente como un individuo o sea los grupos de target más reducidos. Esto marca una tendencia al customized products.

La TV digital reconfigura el lenguaje audiovisual, desde las formas de acceso a la TV hasta la forma de mantenimiento económico. La producción de contenido debe pasar por transformaciones profundas en función de la interactividad y los modelos tecnológicos. El televidente que hasta ahora asumía una posición prioritariamente pasiva, pasa a ser más activo en la TV Digital, participando de la producción de contenido como ya sucede en Internet.

\section{Conclusiones}

\subsection{Propuesta de Producción Multiplataforma}

El proceso multiplataforma que se utiliza hoy consiste básicamente en producir para televisión en alta definición y convertirlo para los diversas plataformas. O sea, de una secuencia de tomas se obtiene un producto final, a ese producto se lo convierte a distintas plataformas. 
Figura III. Proceso clásico de producción audiovisual

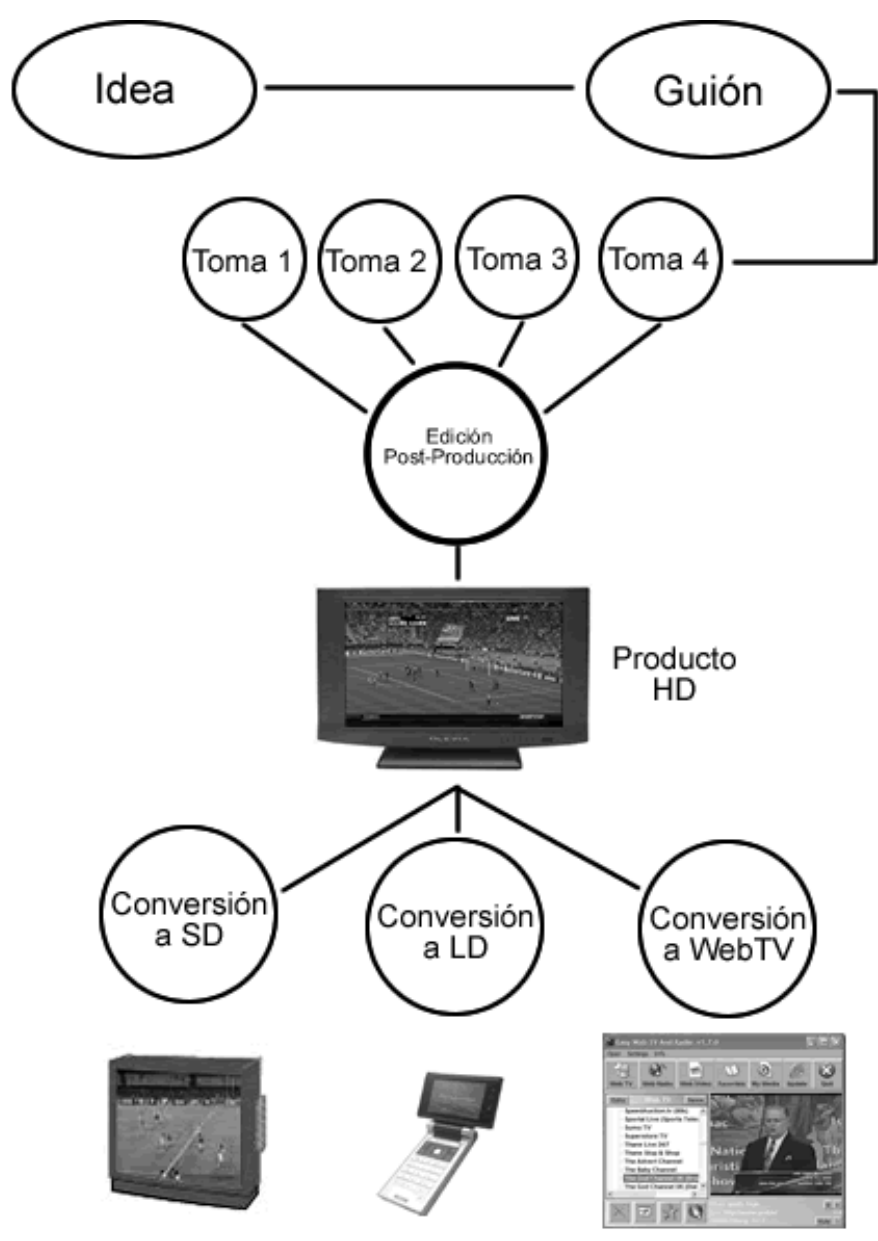

Fuente: Elaboración propia.

Esto no es una práctica que sea eficaz para las distintas plataformas porque cada una tiene sus particularidades. La producción considerando que el producto se difundirá en diversas plataformas debería partir de guiones, planillas técnicas, etc. que incluyan tomas específicas de video y audio e incluso en post-producción que permitan generar el producto adaptado a cada plataforma. O sea, diversas tomas generan diversos productos audiovisuales. 
Figura IV. Proceso de Producción Multiplataforma

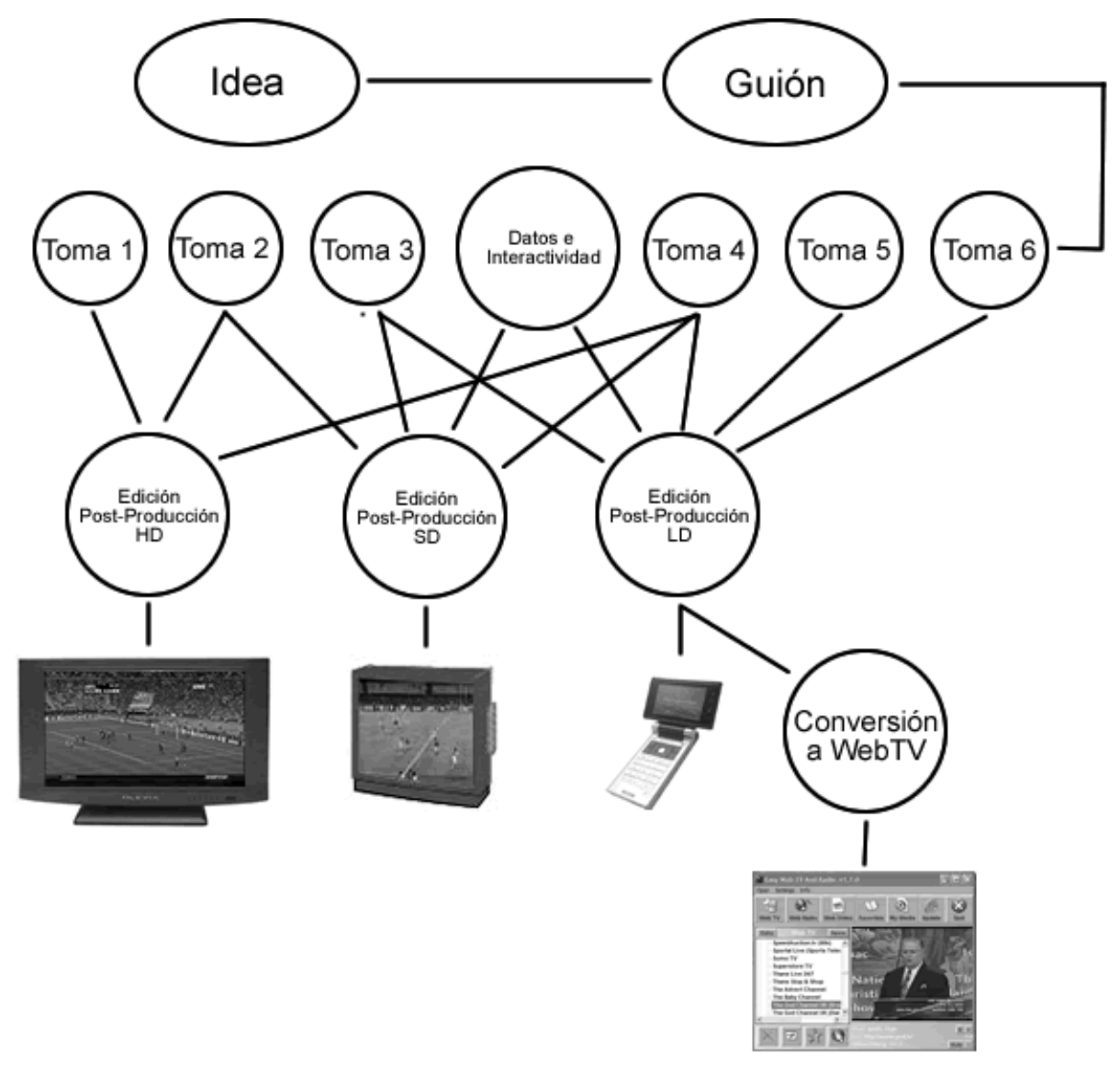

Fuente: Elaboración propia.

Además, considerando las nuevas posibilidades de la TV Digital y de Internet, si se utiliza Interactividad los productos deberán considerarla desde el origen igualmente para la inclusión de datos adicionales o las reediciones.

Se requiere que el creativo audiovisual proponga un replanteo narrativo y cambie la forma de concebir cada producto dado la multiplicidad de plataformas o "ventanas" a través de las cuales podrán ser exhibidos. También se requiere una gran adaptabilidad para el uso de herramientas y recursos tecnológicos y principalmente requiere una forma global de dirigir el proceso de producción y concebirlo desde el pensamiento en red. El creativo y productor deberá tener una visión transversal más que enfocada en una línea tecnológica. 
Pensar en multiplataforma amplía las posibilidades de inserción de un producto en el mercado comercial. Esto favorece el pitching o venta directa de los guionistas a las distribuidoras y le permite llegar a los interesados con mayores posibilidades (GARCÍA SERRANO, 2010).

Pensar en multiplataforma será, en poco tiempo, una necesidad para el éxito de los productos audiovisuales.

\section{Bibliografía}

GALINDO RUBIO, Fernando "El audiovisual en la telefonía móvil 3G.Consideraciones formales para una comunicación eficaz". http://www.ehu.es/zer/zer19/zer19 10.pdf Fecha de consulta: 8 de agosto de 2010

GARCÍA SERRANO, Federico." Las técnicas del "Pitching" en el mercado audiovisual español: del "caramelo" al Guión". Universidad Complutense, Madrid. http://eprints.ucm.es/8577/1/Pitching del caramelo al guion.pdf Fecha de consulta: 8 de agosto de 2010

JODAR MARIN, J. (2009) "La era digital: Nuevos medios, nuevos usuarios y nuevos prfesionales". En Razón y Palabra. www.razonypalabra.org.mx Fecha de consulta 8 de agosto de 2010

MARTIN, M. (1962). "La estética de la expresión cinematográfica”. Ed. Rialp. Madrid.

NEGROPONTE, N. (2000). El mundo digital. El futuro que ha llegado. Ediciones B., Barcelona.

ORIHUELA, J.L. "Sociedad de la información y nuevos medios de comunicación pública:claves para el debate". En Nueva Revista. Disponible en Internet en: http://www.unav.es/digilab/nr/ Fecha de consulta: 8 de agosto de 2010.

\section{Forma de citar este artículo en bibliografías}

LIENDO, C.; SERVET, P.; (2010): "Pensar para la Producción Audiovisual Multiplataforma para TV Digital”, en Revista PANGEA, 1, páginas 199 a 213. Red Académica lberoamericana de Comunicación. Recuperado el _ de _ de 2_ de: http://revistaraic.files.wordpress.com/2012/01/01-01-110.pdf 
i Diccionario de la Lengua Española - Vigésima segunda edición 1. adj. Inform. Dicho de una aplicación o de un producto informático: Que puede ser utilizado por distintos sistemas o entornos.

ii http://www.comfer.gov.ar/web/ley26522.pdf

iii http://www.comfer.gov.ar/web/blog/?p=2551

iv http://es.wikipedia.org/wiki/Plataforma_\%28inform\%C3\%A1tica\%29

v Interactividad Completa: es la interactividad entre el usuario y el producto audiovisual, que involucra información Compartida desde y hacia servidores existentes en Internet como también en el entorno del usuario.

vi Interactividad Local: es la interactividad entre el usuario y el producto audiovisual, que se resuelve en el entorno del usuario, sin requerir una conexión a Internet u otra red externa. 